\title{
Evaluating Implementation of Web-Based Teaching in Political Science
}

\author{
G. David Garson, North Carolina State University
}

$T_{\text {the }}^{\text {he }}$ here is increasing interest in the use of the World Wide Web for teaching purposes. Interest is increasing because, as Sheryl Burgstahler has noted, the web "provides new ways for us to teach and learn. It allows us to do new things, as well as to do traditional things in new ways" (1997, 63). Others, such as Peter Denning, associate dean for computing at George Mason University, have gone further, arguing that the rise of web-based teaching heralds the "demise of the university" $(1996,29)$, as information technology erodes the four traditional cornerstones of the university:

1. The library as a physical place is soon to be replaced by digital libraries accessible worldwide by almost anyone

2. The "community of scholars" around the library is soon to be replaced by communities of specialists linked electronically, divorced from geographical location 3. The ideal-typical small undergraduate class has become unaffordable and is incapable of competing with commercially-provided education on the bases of economics, production values, and entertainment quotient

4. Job structure has changed such that universities can no longer hope to prepare students for or promise them a "lifelong career," the central selling point until recently.

In his testimony to the National Science Foundation, Denning then

G. David Garson is professor of public administration at North Carolina State University, where he teaches courses on computer applications, GIS, and research methodology. Editor of the Social Science Computer Review, he is also author or coauthor of 16 books and over 50 articles on public administration, computer applications, and political science. He may be contacted at David_Garson@ncsu.edu. asked, "What roles can universities fulfill that people would find valuable?" He answered his own question by asserting that universities' salvation lay in their ability to use the Internet and information technology as delivery tools while looking for new, primarily adult, learners.

In political science, most major American Government textbooks have correlated web sites. Many political scientists have begun to put their courses on the web, although usually in relatively limited ways. This article describes a more extensive experiment in web-based political science education for an introductory course in American government. The experiment was characterized by the absence of lectures, no classroom attendance requirement, use of an online textbook-related workbook, online readings in place of reserve room reading, online research in place of library research, an electronic discussion group in place of discussion sections, and email for advising of students. The major traditional course elements in the experiment were the use of a print textbook (Burns et al. 1997), traditional (offline) midterm and final with structured and essay items, and a writing requirement.

\section{The Structure of the Web- Based Instructional Experiment}

\section{Methodology}

Two sections of Introduction to American Government taught by different instructors were offered at North Carolina State University (NCSU) in the second summer session of 1997. One was web-based and one traditional. Objective preand post-tests were administered to the two populations for assessment purposes, and the results are reported here, along with anecdotal student comments. The experiment was exploratory only, without such scientific controls as random assignment of subjects.

The objective pre- and post-tests were based on a generic survey instrument developed by Ken Janda, Jeff Berry, and Jerry Goldman for use in introductory American Government classes. The survey poses questions addressing interest and knowledge about politics, political beliefs, experience with computers, and respondent background. The survey was administered in the present experiment in traditional paper format without grade, under conditions of anonymity. ${ }^{1}$

Both survey groups were summer school sections, which normally meet every day for six weeks to cover the material presented in 15 weeks of a regular fall or spring semester. The traditional section $(n=31)$ met in this fashion. Attendance was not required in the web-based section $(n=20)$, although the instructor was available in a lab classroom three days a week at a preannounced time. The two sections differed in several ways. Students in the traditional section had a higher GPA (2.53 compared to 2.29), were much less likely to have taken the course because it was a requirement ( $21 \%$ to $59 \%$ ), were correspondingly much more likely to have taken the course because of interest in politics $(65 \%$ to $29 \%$ ), were more likely to be seniors ( $41 \%$ to $12 \%$ ), had more total hours passed (62.6 compared to 47.2 ), and were more likely to be men ( $68 \%$ to $48 \%$ ). Students in the traditional section were just as likely to have a computer in their room as students in the web-based section and, at the start of the term, were more likely to access the Internet at least twice a week ( $78 \%$ to $53 \%)$. In general, 
Figure 1

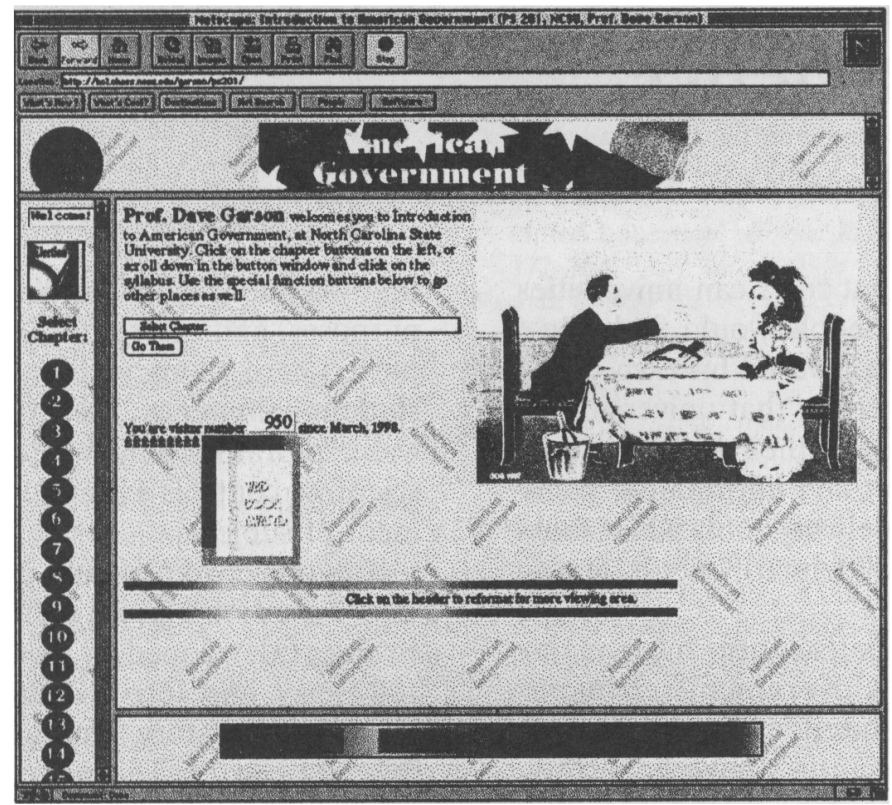

Home Page for Introduction to American Government

(http://hcl.chass.ncsu.edu/garson/ps201/)

then, success factors were more prevalent in the traditional section.

\section{Web-Based Class Structure}

Figure 1 shows the Introduction to American Government home page. The menu frame on the left allows access at all times to any of the fifteen "weekly" topics, as well as to the class syllabus, the class electronic discussion list (listserv), and the class home page.

The web site (http://hcl.chass.ncsu. edu/garson/ps201/) also includes:

- "Something to Think About," an electronic analog of the "icebreakers" often used in lecturebased pedagogy

- Online main and alternative readings

- "Politics in Action," online exploratory activities for students

- "Internet Research," structured research assignments and openended links to sites related to the chapter topic

- "Newsbreaks," current events summaries taken from The New York Times, The Wall Street Journal, CNN News, and other sources, with accompanying discussion questions

- Three sets of interactive review questions in multiple choice, true- false, and fill-in-the-blanks formats, with online hints and scoring - "Political Analysis," three essay questions for each chapter, most with Internet research links - "Net Search," links for online searching via Altavista, Lycos, and Yahoo

- "We the People" and "A Closer Look," special topics features, usually graphical in nature - Online chapter summaries and lists of learning objectives by chapter.

The web site provides students with several megabytes of original materials, plus custom gateway access to the almost unlimited resources of the World Wide Web.

\section{Evaluation of the Web- Based Instructional Experiment}

In this section, I evaluate the experiment from the viewpoints of the student, faculty member, and institutional administration, though, admittedly, these perspectives overlap.

\section{Student Evaluation Factors}

Ease of research

In addition to having all needed research sources accessible online, found materials become part of a permanent searchable database that can be cut and pasted into writing assignments. However, many students in introductory courses may attach more importance to taking a section where no research is required in the first place. In the experimental section, students cited the writing requirement as one of the three top negatives (five 3-5 page research papers were required).

\section{Interest}

Student interest varies. Outstanding lecturers will probably always outperform web-based methods of instruction when it comes to attracting and holding student interest. However, web-based methods can employ color graphics, audio clips, and even movies. Multisensory learning, such as is reflected in web-based teaching, has routinely been found to be more effective pedagogically than unisensory learning such as reliance on texts alone (see Carr 1996). However, these oft-cited advantages are theoretical and may apply only to some students. Students rated convenience higher than interest factors and reported that not having traditional lectures and face-to-face discussions were disadvantages of web-based instruction.

\section{Costs}

Web-based instruction provides some marginal cost benefits to students. Online readings saved students the cost of coursepaks and in some cases the cost of workbooks. Additionally, not having to attend classes reduced some students' transportation expenses. The flexibility of web-based instruction may also benefit students financially by allowing them to work rather than attend class. However, students still have to purchase the textbook and cost savings seems not to have been a major consideration.

\section{Structure}

Structure, in the form of firm lesson plans, required attendance, and graded homework, is often a plus for introductory students, who want 
clear information on what they are supposed to do, how they are supposed to do it, and how they will be evaluated. The web-based course was laid out in advance in great detail. Every unit has an overview and written learning objectives. The online workbook provides a self-regulating form of pacing one's learning and gives students instant feedback. Students rated having an online workbook as the third most valuable feature of the web-based course.

The complete availability of the instructor, freed from lecture duties, for individual and small-group help during most class sessions might also be considered a structure-related factor. However, while all but one student rated the instructor as "somewhat" or "very" helpful, similar ratings were given by students in the traditional course. Although students in the web-based section could receive more help than students in the lecture section, help is directly related to attendance. Since attendance was much lower in web-based sessions, faculty helpfulness was difficult to assess. Introductory students may be less capable of independent learning required in web-based education and, as one evaluation response put it, "There should be more mandatory attendance days in class because some students need structure, and enforced attendance." The most common suggestions for improvement in the web-based section had to do with requiring attendance, requiring papers to be turned in once a week rather than at the student's discretion, and providing some overview lectures to give the "big picture" (even though chapter overviews were on the web). An illustrative post to the class discussion list read, "I really believe that there should be attendance at least once a week. That way you have to be there and you know that things will get discussed."

\section{Course "Passability" \\ Many students view courses from a utilitarian viewpoint: they weigh the progress-toward-degree benefit in relation to effort cost. Many " $\mathrm{A}$ " and " $B$ " students have done well in}

a traditional format, know they are successful in it, and prefer to stick with it rather than try an unknown. Less-able students seeking only to "slide by" may conclude that less effort is involved in passively attending lectures and taking mainly multiple-choice exams. The interactivity of web-based education requires greater student attentiveness, responsiveness, and effort. Also, if a web-based instructor chooses to create additional assignments in lieu of the lectures and discussions (e.g., in the experimental course, students were required to do 15 outside readings and 5 short research papers based on Internet research), students will likely view these assignments as additional effort compared to traditional sections. Abolishing such assignments would improve the utility ratio for students but would diminish one of the pedagogical values of web-based instruction, namely freeing student time for other important learning tasks.

\section{Convenience}

Ideally, web-based instruction allows students to learn what they want, when they want, and where they want. In fact, convenience factors may weigh heavily in a student's decision to take a particular course. Students in the web section gave their highest ratings to the following web benefits, all of them convenience factors: ability to work away from class; ability to work when it fits a time schedule; and having readings available online instead of in the library. The first two were cited twice as often as the third.

\section{Amount Learned}

An attempt was made to assess how much students learned, by administering an instrument developed by Janda, Berry, and Goldman (http:/court.it-services.nwu.edu/ survey/finder.pl?dataset $=1$ ). Students in the traditional section had higher average GPAs, interest levels, and hours passed than students in the web section, and consequently scored higher in the pre- and posttests. The relevant comparison, then, would be the degree of improvement rather than the average test score. On this basis, there was more improvement in the traditional section on 6 items, similar improvement on 3 items, and more improvement in the web-based section on 3 items. On two items, student success declined on the post-test, but decline was less in the traditional sections. Cut another way, student performance in the web-based class caught up with that of students in the lecture class on 6 items and did not catch up on 8 items. These results are difficult to interpret since neither section made any conscious effort to cover the material in the items on the post-test. Where one section covered the material, as when the traditional section discussed comparative national tax rates, student success went up dramatically on a question requiring identification of the country with the lowest tax rate. Students in the web-based course covered 675 items not related to the post-test and tests showed students retained knowledge of $83 \%$ of these items on the structured portions of the midterm and final.

My interpretation of these data is that in terms of amount learned, it is not clear that web-based instruction is significantly better or significantly worse than traditional instruction. A lesson I draw is that instructors will need to go beyond sole reliance on web-based learning to models that combine important traditional elements with new technology and media. As one student commented on the web-based class discussion list:

\begin{abstract}
This is a fun class. Although it is possible to do well in this class without attendance at every class, I think a flexible attendance policy, with five or six scheduled and required lectures may enhance the lesson. Lectures on American politics are not always the most interesting things on earth, but a compact and efficient lecture would greatly increase my understanding of some subjects that multiple choice questions don't detail.
\end{abstract}

Of course, online coverage and subsequent tests in the web-based section had more than multiple-choice questions, but the statement illustrates the tendency of students to 
hone in only on segments they believed would be "on the test," such as items in the online test item bank. In comparison, in the traditional section, the "captive audience" associated with the lecture format assured most students would be forced to be exposed to broader course themes.

\section{Satisfaction}

The web-based section was reasonably popular, but not more popular than the traditional section. In the web-based section, all but two students reported they would recommend it to other students; only two students disliked the course; and all but one student found the instructor helpful. These positive results came about even though, despite widespread advertising, all but one student signed up for the web-based section unaware of its radically different structure and requirements. It is important to note, however, that $50 \%$ of the students in the webbased section stated on the post-test that they prefer the traditional format. It should also be noted that web-based instruction holds students accountable in ways that may be tied to student dissatisfaction. Because students want both traditional and new media components, use of webbased instruction as a supplement to rather than a replacement for the lecture method is often found to be satisfying and popular with students (see Bee and Usip 1998; Schneider 1998).

\section{Faculty Perspective Factors}

\section{Preparation Time}

Putting materials on the web requires extra preparation time in terms of processing documents, creating graphics, and learning web authoring tools. To fully move a course online might easily require full faculty release for one semester to develop. This development time could be cut considerably, however, by use of existing online components from textbook publishers, colleagues' web sites, and by reducing multimedia and online test elements. Initially, course preparation time is significantly greater for web-based instruc- tion than for lecture-based teaching. However, once a web-based course is developed and a faculty member has gained web-authoring competencies, updating its content requires no more time than updating a lecture course does (until the faculty member and/or textbook changes content coverage, requiring redevelopment).

Development and maintenance time may be captured through dropping such things as face-to-face discussion groups and substituting electronic "equivalents." However, not a single student in the web-based course rated the online discussion group as a positive. No doubt, online discussion could be improved compared to that in this particular implementation, but the study does suggest there is great challenge involved in attempting to make electronic discussion substitute for faceto-face discussion. Pressure exists to introduce live overview lectures and face-to-face class discussions as a supplement to the online material, thereby increasing preparation time in web-based sections compared to traditional ones.

\section{Contact with Students}

By eliminating lectures, web-based instruction means that class time can be used entirely for direct one-toone and small group discussions with students. The instructor can circulate around in the room assisting students with problems, making suggestions about papers and projects, debriefing students on their writing assignments, and carrying on substantive discussions of the study topics. Electronic mail also allows for direct faculty-student communication. Greater contact in web-based instruction is, of course, only available to students who choose to attend class help sessions and/or participate in email and online discussion.

\section{Professional Currency}

Whereas printed books and journals commonly present materials a year or more out of date, web-based teaching permits faculty and students to use new information as soon as it becomes available. The "Newsbreak" feature on the course web page used for this experiment and the online readings demonstrated this. If "staying on top of one's discipline" is a paramount academic virtue, online courses provide a means for exercising this virtue.

\section{Performance Evaluation}

Many colleges use student evaluations as a measure of faculty performance. There are reasons for faculty apprehension peculiar to web-based instruction. Reactions arising from the experiment described in this article suggest that students who accept using a two-year-old textbook tend to think all web documents should always be up to the minute. They also have little tolerance for downtime, or just plain slow speed-alltoo-frequent networking realities. Frustration can also be displaced onto the faculty member. Students may view web presentations as they would watch shows on television, a standard with which faculty cannot compete. Moreover, students may want traditional lectures and discussions and feel the instructor should be doing all the traditional work and all the web-based work as well. Finally, the half of the students who take advantage of the convenience factors of web-based education and attend few or no class sessions may fail to identify in any positive way with the instructor, causing an "out of sight, out of mind" performance evaluation syndrome. Students are likely to interpret faculty performance questionnaire items mostly in terms of their existing frame of reference, which is the lecture method, and, indeed, university student evaluation forms thus far do not contain items on topics like web pages.

\section{Institutional Perspective Factors}

\section{Faculty Personnel Support}

As one writer noted of web site development, "Designing a web site is a team effort. If someone insists that he can do the entire job alone, pass him up" (Snyder 1996, 96). Ideally, a four-member team is needed, consisting of a content specialist 
(perhaps the faculty member), a graphics designer, a programmer, and a web designer. I note that in my personal experience, the typical cost for devel-

oping an educational CD-

ROM for commercial distribution is two or three hundred thousand dollars because what is involved is more than a single individual can reasonably be paid to do-a team is required.

\section{Equity}

One of the

most common

observations in

the literature on the social impacts of computing is that women and minorities suffer bias in terms of computer-related outcomes (see review in Garson 1995, 154-62). While this is naturally of institutional concern, it should be noted that this literature focuses on computer science instruction and predates web-based instruction in disciplines like political science. Although the experiment described here did not collect evidence relevant to gender bias, it may be noted that the web-based American government section had substantially more women than men.

\section{Discussion}

Successfully implementing online education requires the involvement of self-motivated students who have independent learning and writing skills and who have access to good equipment. The University of Wis- consin, Stout, has developed a model of online education which comes with the warning: "Online courses can be invigorating, personally motivating, and highly rewarding, but not all learners reap these benefits. Computer-based learners are: comfortable writing, are able to motivate themselves to complete assignments, and have the requisite equipment and connectivity" (http://major. uwstout.edu/). The present experiment provides additional evidence in support of this viewpoint.

Web-based instruction in American government is not likely to be the cost-saving panacea some administrators think. In fact, implemented poorly, it has the potential to increase costs while diminishing the quality of learning outcomes. On the other hand, implemented well, it can provide a valid educational alternative that will appeal to a substantial number of (but not all) students. If the present experiment suggests a lesson, it is that web-based sections are best seen as part of a mix of offerings rather than as a new mode of instruction displacing traditional forms. Moreover, web-based sections themselves will benefit by avoiding wholesale embrace of technology in favor of a mix of traditional and new components.

A mixed approach might involve a pair of faculty serving as instructors of record for two sections, with one faculty member handling the web- based component and one faculty member handling the lecture/discussion component, albeit lecturing less frequently than in traditional sections. Through pairing, the total workload for one instructor would not rise unacceptably. At the same time, the traditional instructor would benefit from student access to webbased resources and from reducing the number of lectures, freeing time for course development.

Beyond a mixed approach, other recommendations for future implementations of web-based instruction in American government include requiring attendance for the traditional component, as by making lecture and class discussion components part of the exams; reducing added components in the web-based experiment (papers and readings), so total work is perceived by students to be the same as under the traditional method; informing students prior to registration of the nature of the approach and offering traditional alternative sections; providing students with a print version of the online workbook for review purposes while still encouraging use of the online system for feedback purposes; and improving the multimedia elements of the course web pages (e.g., including virtual tutors at key lesson locations, or integrating drill/review/ feedback components with multimedia/exploration components).

In summary, implementation of web-based approaches to the introductory course in American government are apt to be successful to the extent to which, unlike the present experiment, they integrate traditional and technologically innovative educational elements. Such models require a broader vision and a more collaborative approach to educational restructuring at the introductory level than is likely to be the case, or is even possible, with models relying on the efforts of a single faculty member. 


\section{Notes}

1. Others wishing to register their class for this survey may do so online at http://oyez.nwu. edu/goldman/codsurvey.html. The registration process returns a unique URL for each registered class and a second URL where the results of the survey may be accessed. Data allow comparison of a given class with the set of all respondents.

\section{References}

Bee, Richard H., and Ebenge E. Usip. 1998. "Economics: A Discriminant Analysis of Students' Perceptions of Web-Based Learning." Social Science Computer Review 16(1): 16-29.

Burgstahler, Sheryl. 1997. "Teaching on the Net: What's the Difference?" Technological Horizons in Education Journal 24(April): 61-64.

Burns, James MacGregor, J.W. Peltason, Thomas E. Cronin, and David B. Magleby. 1997. Government by the People, Brief Edition. Upper Saddle River, NJ: Prentice-Hall.

Carr, Sherah. 1996. "Hypermedia: The Multisensory Way to Enhance Instruction." (Available online at www.iteachnet.com/ sherahcarr.html).

Denning, Peter J. 1996. "The University's Next Challenges," Communications of the ACM 39(5): 27-31.

Garson, G. David. 1995. Computer Technology and Social Issues. Harrisburg, PA: The Idea Group.

Schneider, Andreas. 1998. "Sociology: The Internet as an Extended Classroom." Social Science Computer Review 16(1): 53-57.

Snyder, Joel. 1996. "Web Lessons Learned." Internet World 7(6): 96-97.

\section{I999 FrankJ. Goodnow Award for Distinguished Service}

The Frank J. Goodnow Award, created by the APSA Council in 1996, honors the contributions of individuals to the development of the political science profession and the building of the American Political Science Association.

APSA's first president, Frank J. Goodnow, exemplified the public service and volunteerism that this award recognizes. Goodnow was the first of many who voluntarily contributed an extraordinary amount of time, energy, and attention to building our dynamic and learned profession.

The Endowments Committee is accepting nominations, including self-nominations, for the 1999 Goodnow Award, to be presented Wednesday' September 1, 1999 at APSA's 95 Annual Meeting.

\section{Deadline for nominations is November 1, 1998}

Please send a letter of nomination and one copy of the nominee's curriculum vitae to:

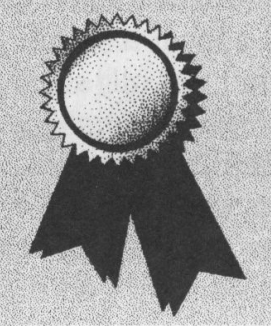

1999 Frank J. Goodnow Award c/o Laura Barrantes American Political Science Association 1527 New Hampshire Avenue, NW Washington, DC 20036-1206

Previous recipients of the Frank J. Goodnow Award

Walter Beach
Pendleton Herring
Warren Miller

Roberta Sigel
Eugene Eidenberg Max Kampelman Jewel Prestage

If you have questions about the nomination process, please contact Laura Barrantes at (202) 483-2512 or lbarrantes@apsanet.org. 